\title{
Clinical Study on the Efficacy of Pantoprazole Combined with Mosapride on Gastroesophageal Reflux Chest Pain
}

CHANG HUI, G. YINGQIANG, YANG ZHICAI, N. XIAOKANG AND YUE LIMING*

Department of Cardiovascular Medicine, Affiliated Hospital of Shaanxi University of Chinese Medicine, Shaanxi 712000, P. R. China

\author{
Hui, et al.: Efficacy of Pantoprazole with Mosapride on GERD
}

To analyse the efficacy of pantoprazole combined with mosapride on gastroesophageal reflux chest pain. A total of 74 patients with gastroesophageal reflux chest pain treated in the Hospital of Shaanxi from June 2016 to June 2017 were enrolled in the study and divided into 2 groups, the combined group and the reference group $(n=37)$ according to the order of admission. The combined group received treatment of pantoprazole and mosapride while the reference group was treated with pantoprazole. Curative effect, recurrence rate and gastroesophageal reflux disease symptom frequency scale were compared between the two groups. The total effective rate of the reference group was $\mathbf{8 3 . 7 8 \%}$, significantly lower than that of the combined group $(97.3 \%, p>0.05)$. Besides, there were 2 cases of recurrence in the combined group, while there were 7 cases in the reference group and this difference is statistically significant $(p<0.05)$. Meanwhile, after treatment the gastroesophageal reflux disease symptom scores of patients in the combined group were significantly better than those in the reference group. The combined treatment of pantoprazole and mosapride has significant curative effect on gastroesophageal reflux chest pain with relatively high effective rate, thus worthy of recommendation in clinical trials.

Key words: Pantoprazole, mosapride, gastroesophageal reflux chest pain

Gastroesophageal reflux disease (GERD) is a condition of contents of stomach and duodenum refluxing in to the esophagus and the patients would experience heart burn, chest pain both of which greatly affect the quality of life $\mathrm{f}^{[1,2]}$. It is a common disease in current clinical practice and has a rising trend. Damage to esophageal mucosa can be seen on gastroscopy ${ }^{[3,4]}$. Traditionally, the treatment for GERD should be focused on symptom control and abundant data from randomized trials showed benefits of inhibiting gastric acid secretion in patients with GERD. Treatment with proton pump inhibitors (PPIs) controls reflux esophagitis in $83 \%$ of patients with comparable symptomatic relief an outcome that is superior to treatment with histamine 2-receptor antagonists ${ }^{[5]}$. However, GERD patients often present with a wide range of severe symptoms and sometimes do not respond to PPI therapy. Several mechanisms have been proposed for the pathogenesis of refractory GERD, including weak acidic reflux, visceral hypersensitivity and delayed gastric emptying ${ }^{[6]}$. An Asia-Pacific consensus on the management of GERD showed that the use of prokinetic agents either as monotherapy or adjunctive therapy to PPIs might have a role in the treatment of GERD in Asia $^{[7]}$. Prokinetic agents like cisapride, which act on the 5-hydroxytryptamine $(5-\mathrm{HT})_{1}$-receptor, have been

*Address for correspondence 
found to be associated with potentially fatal heart rhythm abnormalities. However, mosapride, a selective $5-\mathrm{HT}_{4}$ receptor agonist, is an alternative prokinetic agent that stimulate gastrointestinal motility and gastric emptying, which can be safely used in patients with upper gastrointestinal disorders ${ }^{[7-12]}$. Many studies have shown that mosapride can reduce acid reflux episodes and esophageal clearance of refluxate, theoretically, suggesting potential efficacy in the treatment of GERD $^{[13,14]}$. In a randomized trial, mosapride combined with PPIs achieved a better therapeutic effect than PPI alone ${ }^{[15]}$. However, another clinical trial showed the additional effect of mosapride was limited ${ }^{[16]}$. To fully understand value of combining pantoprazole and mosapride in gastroesophageal reflux chest pain, in this investigation 74 patients with the disease who were treated in the Hospital of Shaanxi were seleced to carry out this study.

A total of 74 patients with gastroesophageal reflux chest pain treated in the Hospital of Shaanxi from June 2016 to June 2017 were enrolled in the study and divided into combined group as well as reference group $(n=37)$ according to the order of admission. In the combined group there were 20 males and 17 females aged 24 to 76 with a mean age of $41.34 \pm 4.53 \mathrm{y}$. In the reference group there were 21 males and 16 females aged 25 to 76 with a mean age of $41.29 \pm 4.84 \mathrm{y}$. There was no obvious difference between the groups in terms of demographic data $(\mathrm{p}>0.05)$. Institutional review board (IRB log number: 441-221) and considering the national regulations that govern the protection of human subjects.

The reference group were treated with pantoprazole (Zhunzi H19990173, Jinzhou Jiutai Pharmaceutical Co. Ltd.), $40 \mathrm{mg}$ on an empty stomach; The combined group received $40 \mathrm{mg}$ of pantoprazole orally $30 \mathrm{~min}$ before breakfast plus $5 \mathrm{mg}$ of mosapride (Zhunzi H20103629, Hunan Warner Pharmaceutical Co. Ltd.) orally 3 times/d.

The curative effect and GERD symptom frequency scale were compared between the 2 groups. Significant effectiveness was seen in some patients, where clinical symptoms like hyperaemia and oedema disappeared on gastroscopy with full improvement of ulcer; Effectiveness was seen in some other patients where hyperaemia and oedema were alleviated under gastroscopy with the ulcer improved; Ineffectiveness was noted in cases the outcome failed to meet the above criteria (total effective rate=significant effectiveness rate+effectiveness rate) ${ }^{[5]}$.

The SPSS 20 software was used as a statistical tool. The enumeration data were described as $n, \%$ and checked by $\chi^{2}$. The measurement data were expressed mean \pm standard deviation and $t$ test was used to determine significance at $\mathrm{p}<0.05$.

The total effective rate of the reference group was $83.78 \%$, which was significantly lower than that of the combined group which was $97.3 \%,(p>0.05)$ as shown in Table 1. After treatment, the GERD symptom scores

TABLE 1: COMPARISON OF TOTAL EFFECTIVE RATE BETWEEN THE TWO GROUPS

\begin{tabular}{lccccc}
\hline Group & Case $(\mathbf{n})$ & $\begin{array}{c}\text { Significant } \\
\text { effectiveness (n) }\end{array}$ & Effectiveness (n) & $\begin{array}{c}\text { Ineffectiveness } \\
(\mathbf{n})\end{array}$ & $\begin{array}{c}\text { Total effective rate } \\
(\%)\end{array}$ \\
\hline Combined group & 37 & 25 & 11 & 1 & 97.3 \\
Reference group & 37 & 14 & 17 & 6 & 83.78 \\
$\mathrm{X}^{2}$ & - & - & - & - & 8.24 \\
$\mathrm{P}$ & - & - & - & - & $<0.05$ \\
\hline
\end{tabular}

TABLE 2: COMPARISON OF GERD SYMPTOM SCORES BETWEEN THE TWO GROUPS

\begin{tabular}{lccc}
\hline Group & Case $(\mathrm{n})$ & Before treatment (score) & After treatment (score) \\
\hline Combined group & 37 & $24.04 \pm 4.76$ & $15.67 \pm 3.87$ \\
Reference group & 37 & $23.87 \pm 4.68$ & $20.02 \pm 4.52$ \\
$\mathrm{X}^{2}$ & - & 1.05 & 7.62 \\
$\mathrm{p}$ & - & $>0.05$ & $<0.05$ \\
\hline
\end{tabular}

TABLE 3: COMPARISON OF DISEASE RECURRENCE RATE BETWEEN THE TWO GROUPS

\begin{tabular}{lcccc}
\hline Group & Case $(\mathbf{n})$ & Recurrence $(\mathbf{n})$ & Non recurrence $(\mathrm{n})$ & Recurrence rate $(\%)$ \\
\hline Combined group & 37 & 2 & 35 & 5.41 \\
Reference group & 37 & 7 & 30 & 18.92 \\
$\mathrm{x}^{2}$ & - & - & - & 8.24 \\
$\mathrm{p}$ & - & - & - & $<0.05$ \\
\hline
\end{tabular}


of patients in the combined group were significantly better than those in the reference group $(p<0.05)$, but the scores were not different between these groups before treatment as shown in Table 2. There were 2 cases of recurrence in the combined group while there were 7 cases in the reference group and the difference between the 2 groups was statistically significant $(\mathrm{p}<0.05)$ as shown in Table 3.

GERD is a common disease with motility disorders of upper gastrointestinal tract mainly caused by a variety of mechanisms and frequently occurring in the patients within $1 \mathrm{~d}^{[17-19]}$. The cause of morbidity is that with injured or weakened defence mechanism in the patients, the intensity, frequency and function time of attacking factor are beyond the capability of body defence, which will have a great impact on the patient's normal life ${ }^{[20,21]}$. In current clinical practices it is commonly treated by inhibitors of gastric acid secretion which reduce the acidity of the esophageal reflux contents in these patients.

The gastroesophageal reflux chest pain is mainly due to lower esophageal sphincter disorder, which causes the reflux of the contents of gastrointestinal tract to esophagus and leads to damages to esophageal membrane in the patients ${ }^{[22]}$. Pantoprazole, a PPI, is prone to aggregation in the acidic environment and shows its effect on gastric parietal cells to reduce gastric acid response ${ }^{[23]}$. Pantoprazole, an irreversible PPI, is effective as a drug for the treatment of GERD can significantly reduce gastric acid concentration and eradicate the chest pain in the patients with GERD as well as infected with Helicobacter pylori. Under acid environment of parietal cell, it can be activated as cyclic sulfonamide, which will play an important role in overall improvement of clinical symptoms. Patients may suffer from headache or diarrhoea during the period of drug use and a small number of patients may experience adverse reactions like nausea, abdominal pain and pruritus ${ }^{[24-26]}$.

It is usually believed that $\mathrm{pH}=4.0$ is the standard to judge whether there is invasiveness in gastric juice. When $\mathrm{pH}>4.0$, gastric juice will activate pepsin and further induce such symptoms as heartburn, therefore the gastric $\mathrm{pH}$ value is required to be under effective control in clinical treatment. At the same time, reflux esophagitis patients also have clinical symptoms like bile reflux, which causes moderate damages to their oesophageal mucosa. Acid-suppressive drug treatment alone, when applied in some patients, fails to give rise to satisfactory results, making it necessary to combine with the drugs which enhance digestive tract motion.

Mosapride citrate is a new type of gastrointestinal motility drug. It can selectively stimulate the 5-HT4 receptor in the digestive tract mucosa neuroplexus, facilitate the release of physiological acetylcholine with digestive tract motility promoting action, increase the contraction amplitude of esophageal peristalsis, shorten the exposure time of esophageal acid, reduce reflux and improve clinical symptoms of reflux esophagitis in the patients. As a new generation of gastrointestinal prokinetic agents, highly selective 5-HT4 receptor agonists activate cholinergic nerves in gastrointestinal tract and produce digestive tract motility with moderately ideal effect in both short and long term followed by no obvious side effects after treatment.

In the gastroesophageal reflux chest pain the treatment of pantoprazole with mosapride can play the combined effect of the two drugs to rapidly improve clinical symptoms, enhance digestive ability, alleviate the injury to oesophageal mucosa, decrease the symptoms like heart burn as well as chest pain in the patients and produce better and faster clinical relief, thus improving their quality of life.

In this clinical study, the total efficiency rate was 83.78 $\%$ in the reference group and $97.3 \%$ in the combined group, which indicated that the combined treatment is more effective. Meanwhile, after treatment the GERD symptom scores of patients in the combined group were significantly better than those in the reference group, which demonstrate the relationship of different treatment method with improvement of symptoms. Above all, the combined treatment of pantoprazole and mosapride has significant curative effect with a greater efficacy rate and is able to greatly improve the symptoms, thus worthy of recommendation and application in clinical practices.

\section{Conflict of interest:}

No conflict of interest between any of the authors.

\section{REFERENCES}

1. Dingliang $H$, Bo Z, Yukun $M$. Efficacy and safety of lansoprazole combined with mosapride in therapy of gastroesophageal reflux. Clin Med Engg 2015;22:473-4.

2. Yingying L, Leilei S. Clinical effect of bella and mosapride on senile reflux esophagitis. Chin Foreign Med Treat 2015;34:128-9.

3. Xiumei W, Billy M. Curative effect of mosapride, omeprazole 
and hydrotalcite on gastroesophageal reflux disease. Chin Health Stand Manag 2015,6:96-7.

4. $\mathrm{Ru} \mathrm{Z}$, Zhenglei X, Jun Y. Clinical effect of bella and mosapride on gastroesophageal reflux disease. Guide Chin Med 2014;12:222-3.

5. Yufen W. Curative effect of mosapride, omeprazole and hydrotalcite on gastroesophageal reflux disease. Jilin Med J 2013;34:5855-6.

6. Moayyedi P, Santana J, Khan M, Preston C, Donnellan C. Medical treatments in the short term management of reflux oesophagitis. Cochrane Database Syst Rev 2007;2:CD003244.

7. Fass R, Gasiorowska A. Refractory GERD: what is it? Curr Gastroenterol Rep 2008;10:252-7.

8. Fock KM, Talley NJ, Fass R, Goh KL, Katelaris P, Hunt $\mathrm{R}$, et al. Asia-Pacific consensus on the management of gastroesophageal reflux disease: update. J Gastroenterol Hepatol 2008;23:8-22.

9. Carlsson L, Amos GJ, Andersson B, Drews L, Duker G, Wadstedt G. Electrophysiological characterization of the prokinetic agents cisapride and mosapride in vivo and in vitro: implications for proarrhythmic potential? J Pharmacol Exp Ther 1997;282:220-7.

10. Toga T, Kohmura Y, Kawatsu R. The 5-HT4 agonists cisapride, mosapride, and CJ-033466, a Novel potent compound, exhibit different human ether-a-go-go-related gene (hERG)-blocking activities. J Pharmacol Sci 2007;105:207-10.

11. Potet F, Bouyssou T, Escande D, Baró I. Gastrointestinal prokinetic drugs have different affinity for the human cardiac human ether-à-gogo $\mathrm{K}(+)$ channel. J Pharmacol Exp Ther 2001;299:1007-12.

12. Inui A, Yoshikawa $\mathrm{T}$, Nagai $\mathrm{R}$, Yoshida $\mathrm{N}$, Ito $\mathrm{T}$. Effects of mosapride citrate, a 5-HT4 receptor agonist, on colonic motility in conscious guinea pigs. Jpn J Pharmacol 2002;90:313-20.

13. Yoshida NA, Ito T, Karasawa T, Itoh Z. AS-4370, a new gastrokinetic agent, enhances upper gastrointestinal motor activity in conscious dogs. J Pharmacol Exp Ther 1991;257:781-7.

14. Yoshida N, Omoya H, Kato S, Ito T. Pharmacological effects of the new gastroprokinetic agent mosapride citrate and its metabolites in experimental animals. Arzneimittelforschung 1993;43:1078-83.

15. Ruth M, Finizia C, Cange L, Lundell L. The effect of mosapride on oesophageal motor function and acid reflux in patients with gastro-oesophageal reflux disease. Eur J Gastroenterol Hepatol. 2003;15:1115-21.

16. Ruth M, Hamelin B, Röhss K, Lundell L. The effect of mosapride, a novel prokinetic, on acid reflux variables in patients with gastro-oesophageal reflux disease. Aliment Pharmacol Ther 1998;12:35-40.
17. Van Zyl J, Van Rensburg C, Vieweg W, Fischer R. Efficacy and safety of pantoprazole versus ranitidine in the treatment of patients with symptomatic gastroesophageal reflux disease. Digestion 2004;70:61-69.

18. Niaz SK, Quraishy MS, Taj MA, Abid S, Alam A, Nawaz AA, et al. Guidelines on gastroesophageal reflux disease. J Pak Med Assoc 2015;65:532-41.

19. Zohalinezhad ME, Imanieh MH, Samani SM, Mohagheghzadeh A, Dehghani SM, Haghighat M, et al. Effects of Quince syrup on clinical symptoms of children with symptomatic gastroesophageal reflux disease: A double-blind randomized controlled clinical trial. Complement Ther Clin Pract 2015;21:268-76.

20. Takeuchi T, Oota K, Harada S, Edogawa S, Kojima Y, Sanomura $\mathrm{M}$, et al. Characteristics of Refractory Gastroesophageal Reflux Disease (GERD) Symptoms -Is Switching Proton Pump Inhibitors Based on the Patient's CYP2C19 Genotype an Effective Management Strategy. Intern Med 2015;54:97105.

21. Popadynets IR. Comparison of the effectiveness of omeprazole and pantoprazole treatment of gastroesophageal reflux disease in patients with asthma. Lik Sprava 2013;73:47-53.

22. Cohen S, Bueno de Mesquita M, Mimouni FB. Adverse effects reported in the use of gastroesophageal reflux disease treatments in children: a 10 years literature review. Br J Clin Pharmacol 2015;80:200-8.

23. Subramanian CR, Triadafilopoulos G. Refractory gastroesophageal reflux disease. Gastroenterol Rep 2015;3:4153.

24. Matsuhashi N, Kudo M, Yoshida N, Murakami K, Kato M, Sanuki $\mathrm{T}$, et al. Factors affecting response to proton pump inhibitor therapy in patients with gastroesophageal reflux disease: a multicenter prospective observational study. J Gastroenterol 2015;50:1173-83.

25. Xuebin B, Bizhu D, Hongling L. Clinical effect of combined use of modified brilliant red decoction and pantoprazole on gastroesophageal reflux disease. Guangxi Med J 2017;39: 354-6.

26. Bing C. Curative effect of pantoprazole triple therapy on reflux esophagitis. Strait Pharm J 2017;29:102-3.

This is an open access article distributed under the terms of the Creative Commons Attribution-NonCommercial-ShareAlike 3.0 License, which allows others to remix, tweak, and build upon the work non-commercially, as long as the author is credited and the new creations are licensed under the identical terms

This article was originally published in a special issue, "XXXXXX"

Indian J Pharm Sci 2020:82(1)spl issue1; XX-XX 